\title{
Navigation and CAS: is D-Day approaching?
}

\author{
Johan Bellemans
}

Published online: 21 August 2009

(C) Springer-Verlag 2009

During the mid-1990s, for the first time, knee surgeons were confronted with computer navigation: a new technology that promised to become one of the most important innovations in orthopaedic surgery.

Those were the days when better, faster, and cheaper computers became available to everybody, the internet was booming, and we all started buying GPS navigation kits for our cars. At that time, it seemed very logical that 10 years later, we all would be using computers for guiding us through virtually every arthroplasty procedure.

The first CAS publications appeared to confirm these expectations. Surgeons who were using computer navigation achieved better accuracy for parameters that we believed were important $[1-4,6]$. Attempts to improve the ease of use of the systems rapidly followed, surgical robots were developed, and navigation machines were sold as sweet cakes to doctors, hospitals, and implant manufacturers [5].

But look where we are now 15 years later.

Navigation machines are standing in the corridors covered by blankets. Several navigation and robotic companies went bankrupt or stopped their business. Only a minority of surgeons continue to use navigation for their standard technique in total or unicondylar knee arthroplasties, osteotomies, or ACL reconstructions [5].

Why did this happen? How is it possible that a technology that undeniably leads to better surgical accuracy did not break through so far?

The answer I believe lies in the end product of what we aim to achieve as knee surgeons; the final result for the patient.

J. Bellemans $(\bowtie)$

Department of Orthopaedic Surgery, University Hospitals

Leuven, Weligerveld 1, 3012 Pellenberg, Belgium

e-mail: johan.bellemans@uz.kuleuven.ac.be
And this is where the shoe hurts.

Where are the clinical data that confirm that improved accuracy as obtained with navigation leads to better clinical results? Where are the papers that demonstrate better clinical performance or better survivorship for cases operated on with navigation?

We don't see them coming.

In this journal, one or more papers on computer navigated studies are published almost every month, but you won't find a single publication demonstrating undeniable superiority in overall clinical outcome in favour of CAS.

Such reports simply do not exist [1, 2, 4]. And yet, the clinical data must be out there somewhere. Thousands of CAS patients have now been operated with follow-up longer than 10 years.

The fact that nobody has been able to demonstrate clinical superiority in these patients could mean two things. Either there is no clinical superiority, in other words the improvement in surgical accuracy is marginal and of no clinical influence, or secondly, the improvement in accuracy is counteracted by factors such as increased operating time, increased complication rate, or other downsides associated with CAS.

If this assumption is correct, CAS believers are facing hard times ahead.

It would mean that such papers will never come. And as a consequence CAS would disappear. This might sound bizarre in our over-computerized society, but why would we continue to use expensive and cumbersome technology if the final result for the patient is not any better?

Therefore, my friends CAS believers: D-day is approaching for you guys. Either you show us fast that outcome in CAS patients is better, or you lose the battle.

Also, you may not forget that the current socio-economic trend is against you, CAS believers. Retaining quality with 
non-inferiority is the current code sentence for health care politicians. If surgeons can achieve the same quality in end result but at a cheaper price, that will be the way they will force us to go!

But on the other hand, this also may be your golden opportunity! Why don't you try to use CAS for making the procedures cheaper! For a total knee, we need seven boxes of instruments today that need to be transported between centres and sterilized 5 times a week. The costs associated with this inventory traffic and maintenance is enormous. Whereas with a computerized system, you could do the operation in theory just with a navigated saw and chisel! And let us be honest; today, a decent computer only costs a few hundred Euro. Together with a couple of Steinmann pins and six LEDs we are set!

Therefore, my advice to the CAS supporters is to stop focussing on clinical outcome. You will never be able to convince us on that. If CAS could lead to better clinical results, we would have already seen the proof of that by now. Instead, make your machines more user friendly! And cheaper! Then our initial enthusiasm for this technology will return, and knee surgeons will again become eager to use and operate with CAS.
But remember, time is not on your side. The clock is ticking. D-day for CAS is approaching. And it might turn out that the D stands for Disillusion...

\section{References}

1. Bathis H, Shafizadeh S, Paffrath T, Simanski C, Grifka J, Luring C (2006) Are computer assisted total knee replacements more accurately placed? A meta-analysis of comparative studies. Orthopäde 35:1056-1065

2. Bauwens K, Matthes K, Wich M, Gebhard F, Hanson B, Ekkernkamp A, Stengel D (2007) Navigated total knee replacement. A meta-analysis. J Bone Joint Surg Am 89:261-269

3. Chauhan SK, Scott RG, Breidahl W, Beaver RJ (2004) Computerassisted knee arthroplasty versus a conventional jig-based technique. A randomised prospective trial. J Bone Joint Surg Br 86:372-377

4. Ensini A, Catani F, Leardini A, Romagnoli M, Giannini S (2007) Alignments and clinical results in conventional and navigated total knee arthroplasty. Clin Orthop Relat Res 457:156-162

5. Friederich N, Verdonk R (2008) The use of computer-assisted orthopaedic surgery for total knee replacement in daily practice: a survey among ESSKA/SGO-SSO members. Knee Surg Sports Traumatol Arthrosc 16:536-543

6. Victor J, Hoste D (2004) Image-based computer-assisted total knee arthroplasty leads to lower variability in coronal alignment. Clin Orthop Relat Res 428:131-139 